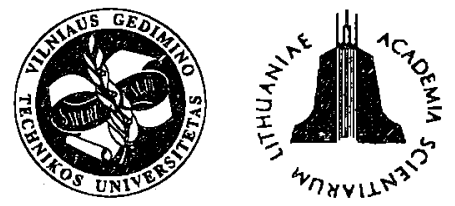

ISSN 1648-4142 TRANSPORT

http:/www.vtu.lt/english/editions

\title{
SIMULATION OF STEVEDORING WORK IN THE KLAIPEDA OIL TERMINAL
}

\author{
Henrikas Pranevičius ${ }^{1}$, Dalius Makackas ${ }^{2}$ \\ Business Informatics Department, Kaunas University of Technology, Studentu g. 56, LT-3028 Kaunas, Lithuania \\ Received 200205 07; accepted 20020910
}

\begin{abstract}
The paper presents the approach of developing simulation models of stevedoring work in oil terminal using aggregate approach and simulation system ARENA. Aggregate approach permits to develop formal specification of simulated systems. Aggregate specification of the system is presented as a set of interacting piece-linear aggregates. Controlling sequences are used for formal description of each piece-linear aggregate. Transformation of aggregate formal specification to ARENA system operators permits to develop a simulation model. The developed model permits to evaluate characteristics of the Klaipeda oil terminal which are used both in queuing theory and analysing timing properties of real-time systems.
\end{abstract}

Keywords: oil terminal, piece-linear aggregates formalism, simulation system ARENA.

\section{Introduction}

The Klaipeda harbour is one of the biggest harbours in the Baltic States (Estonia, Latvia and Lithuania). Reconstruction of the harbour requires a lot of investments and it is important that it would be efficiently used. This problem can be solved applying corresponding models $[1,2,3]$. Models permitting to evaluate metal and container transportation through the Klaipeda harbour are presented in [4]. Presented in this paper created models permit to evaluate the interaction of various kinds of transport means (sea, railway, motor transport) during the transportation of loads; occupation of harbour embankments, loading/ unloading mechanisms, van loading/unloading grounds.

This paper presents a simulation model of the Klaipeda harbour oil terminal. The model permits to evaluate two groups of characteristics. The first group of characteristics is used in queuing theory. Examples of such characteristics are occupation coefficients of embankments, platforms and reservoirs etc. The other group of characteristics is used analysing real-time systems [5]:

- Probabilities that arrived ship finds the needed volume of oil;

- Probability of ship staying time in a harbour is less than some their values, etc.

Creating the Klaipeda harbour oil terminal an aggregate approach [6] was used for the formalisation of terminal operation. The software implementation of a simulation model was done using ARENA simulation system.

The paper is structured as follows: the section $\mathrm{Ag}$ gregate model of the Klaipeda oil terninal contains ag-

\footnotetext{
'E-mail: hepran@if.ktu.lt

2E-mail:damaka@if.ktu.lt
}

gregate specification characteristics of an aggregate model; model formal specification is presented in the second section and the investigation results are given too.

\section{Aggregate Model of the Klaipeda Oil Terminal}

Aggregate approach is widely used for formal description, simulation and validation of complex systems [7]. The general idea of the method is a system decomposed to separate piece-linear aggregates (PLA) and each PLA of the system is described using the method of controlling sequences. The advantage of this approach is its ability to describe the analysed system mathematically strictly.

\subsection{Conceptual Model of Terminal}

The structural scheme of the Klaipeda oil terminal is presented in Fig 1.

The created model represents the transportation of oil products through the Klaipeda harbour in the following ways:

- Oil products are divided into two groups: light and dark, without subsequent details;

- Total amount of reservoir capacities at the Klaipeda oil terminal for dark products is $250,000 \mathrm{~m}^{3}$, and for light products it is $100,000 \mathrm{~m}^{3}$;

- There are four pouring platforms at the terminal: two of them are assigned for dark products, one for light products and one for both light and dark products;

- Maximum 32 tank cars in each platform can be served at the same time;

- There are two embankments at the oil terminal. In the first embankment both kinds of oil products can be 


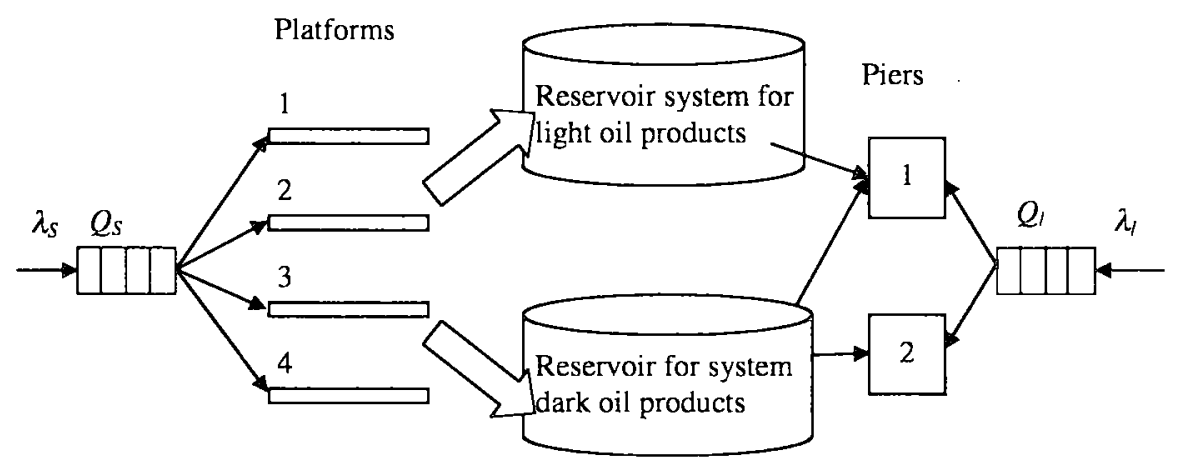

Use of platforms: 1, 2- light oil products; 2, 3, 4-dark oil products

Fig 1. Structural scheme of queuing system which represents transportation of oil products through the Klaipeda harbour

poured and in the second only dark oil products can be poured;

- Trains arriving at the Klaipeda terminal are turned to two queues, one for dark oil products and one for light oil products;

Parameters of the model and simulated characteristics:

- Intensity of orders flow for dark and light oil transportation is $\lambda_{D}$ and $\lambda_{L}$ respectively (number of orders per 24 hours);

- Capacity of one train is $v_{s}$ (tonne);

- Light oil products make $p$-th part of total flow of trains $(p=0.3)$;

- Train of 32 tank cars with oil is served for: a) dark oil products poured out from the train in 8 hours; b) light oil products poured out from the train in 4 hours;

- Equipment pumps 1 kilotons of oil products to a ship in an hour.

Intensities of trains and tankers arriving to oil terminal, depending on volume of exported oil, are presented in Table.

The following characteristics can be simulated:

- $\quad$ average level of oil in reservoirs,

- occupation coefficients of each platform,

- average length of queues with light and dark oil products (amount of tank cars),

Intensities of trains and tankers arriving to oil terminal depending on volume of exported oil.

\begin{tabular}{|c|c|c|}
\hline $\begin{array}{c}\text { Amount of } \\
\text { transported oil } \\
\text { (Megatons) }\end{array}$ & $\lambda_{D}$ & $\lambda_{L}$ \\
\hline 3.5 & 4.09 & 3.82 \\
\hline 4.0 & 3.58 & 3.34 \\
\hline 5.0 & 2.86 & 2.67 \\
\hline 6.0 & 2.38 & 2.23 \\
\hline 7.0 & 2.04 & 1.91 \\
\hline 8.0 & 1.79 & 1.67 \\
\hline
\end{tabular}

- average time of storing of oil products at terminal (days),

- annual amount of transported tons. minal

\subsection{Aggregate Specification of the Klaipeda Oil Ter-}

Aggregate scheme of specification is presented in Fig 2. Specifications of aggregate trains flow, tankers flow and embankments are presented bellow.

Aggregate Trains flow

1. Set of input signals. $X=\left\{x_{1}\right\}$, where $x_{1}=\left(O_{N}, O_{S}\right)$, $x_{1}$ - the order for oil transportation; $O_{N}$ - the number of order, $O_{S}$ - the amount of ordered oil.

2. Set of output signals. $Y=\left\{y_{1}\right\}$, where $y_{1}=\left(O_{N}, O_{S}, N_{T}\right), y_{1}$ - the train has arrived to terminal, $N_{T}$ - number of tank-wagon in a train.

3. Set of external events $E^{\prime}=\left\{e_{1}^{\prime}\right\}$, where $e_{1}^{\prime}-1$. the start of order process.

4. Set of internal events. $E^{\prime \prime}=\left\{e_{1}^{\prime \prime}, e_{2}^{\prime \prime}, e_{3}^{\prime \prime} \ldots\right\}$, where $e_{i}^{\prime \prime}$ - the arrival of $i$-th train to terminal.

5. Controlling sequences. $e_{i}^{*} \mapsto \tau_{i} \in[a, b]$, where $\tau_{i}-$ is uniformly distributed value in interval $[a, b]$. Its semantics is the time interval during which trains for $i$-th order will arrive.

6. Discrete part of state. $v(t)=\left(n(t), O_{1}(t), O_{2}(t) \ldots\right)$, where $O_{i}(t)=\left(O_{N}(t), O_{S}(t), N_{T}(t)\right)$, where $n(t)$ the number of trains with oil has departed.

7. Continuous part of state.

$$
z_{v}(t)=\left(w\left(e_{1}^{\prime \prime}, t\right), w\left(e_{2}^{\prime \prime}, t\right) \ldots\right) \text {. }
$$

8. Initial state. $w\left(e_{i}^{\prime \prime}, t_{0}\right)=\infty, n\left(t_{0}\right)=0.1$.

Time of trains arrival to the terminal is unknown and there are no trains going to the terminal.

9. Transition and output operators. $H\left(e_{1}^{\prime}\right)$ :

$$
n\left(t_{m}\right)=n\left(t_{m-1}\right)+O_{S} / V_{T}
$$

where $V_{T}$ - the capacity of tank-wagon;

$$
O_{i}\left(t_{m}\right)=\left(O_{N}, O_{S}, C_{T}\right)
$$




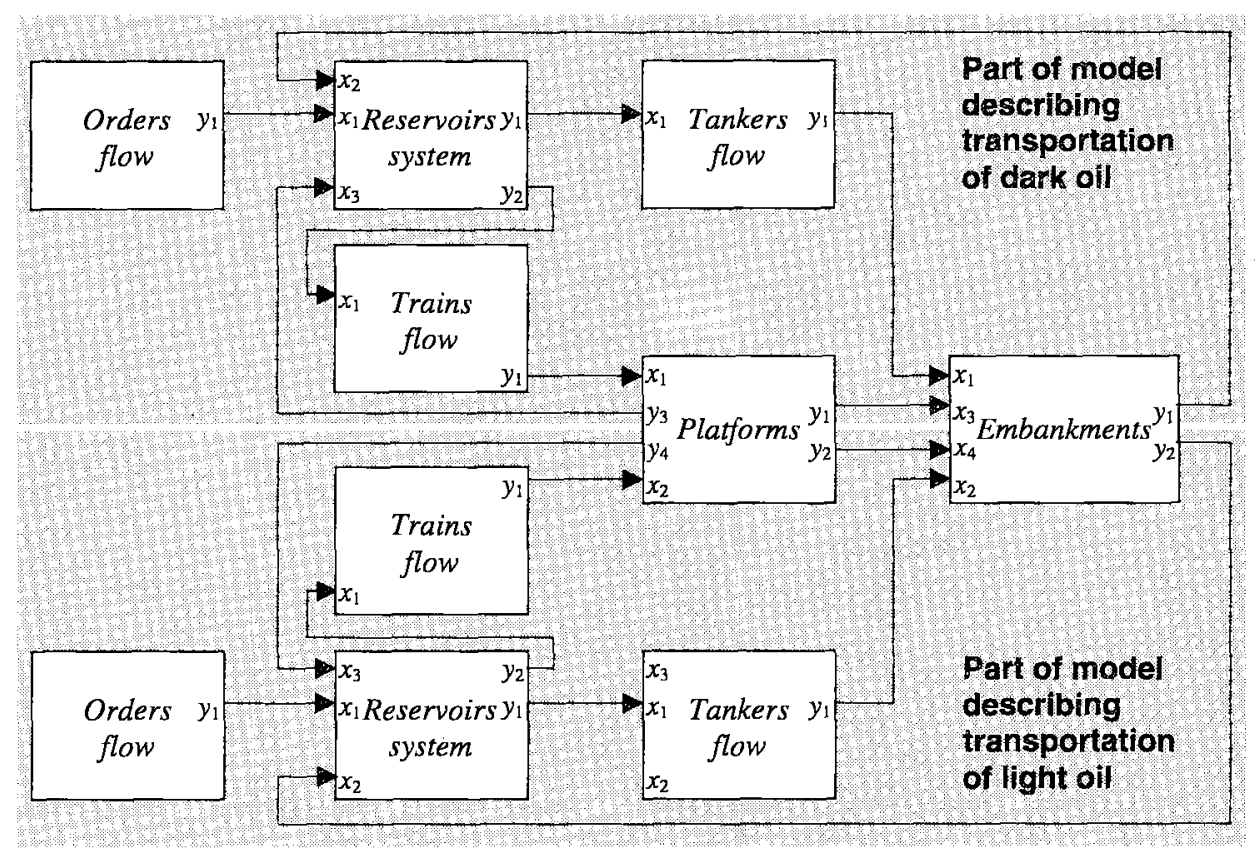

Fig 2. Aggregate scheme of specification

$$
w\left(e_{i}^{\prime \prime}, t_{m}\right)=t_{m}+\tau_{m} /\left(n\left(t_{m}\right)-n\left(t_{m-1}\right)\right) \cdot\left(i-n\left(t_{m-1}\right)\right),
$$

where $i=n\left(t_{m-1}\right)+1, n\left(t_{m-1}\right)+2, \ldots n\left(t_{m}\right)$.

$G\left(e_{k}^{\prime \prime}\right)$ :

$$
Y=\left\{y_{1}\right\}, y_{1}=O_{k}\left(t_{m}\right) .
$$

Aggregate Tankers flow

Meaning of symbols used in this aggregate is the same as in aggregate trains flow.

1. Set of input signals. $X=\left\{x_{1}\right\}$, where $x_{1}=\left(O_{N}, O_{S}\right)$.

2. Set of output signals. $Y=\left\{y_{1}\right\}$, where $y_{1}=\left(O_{N}, O_{S}\right)$.

3. Set of external events. $E^{\prime}=\left\{e_{1}^{\prime}\right\}$.

4. Set of internal events. $E^{\prime \prime}=\left\{e_{1}^{\prime \prime}, e_{2}^{\prime \prime}, e_{3}^{\prime \prime} \ldots\right\}$.

5. Controlling sequences. $e_{i}^{\prime \prime} \mapsto \delta_{i}$, where $\delta_{i}$-the time interval after order start when tanker has to arrive for oil.

6. Discrete component of state. $v(t)=\left(O_{1}(t), O_{2}(t) \ldots\right)$, where $O_{i}(t)=\left(O_{N}(t), O_{S}(t)\right)$.

7. Continuous part of state. $z_{v}(t)=\left(w\left(e_{1}^{\prime \prime}, t\right), w\left(e_{2}^{\prime \prime}, t\right) \ldots\right)$.

8. Initial state. $w\left(e_{i}^{\prime \prime}, t_{0}\right)=\infty$.

9. Transition and output operators. $H\left(e_{1}^{\prime}\right)$ :

$O_{i}\left(t_{m}\right)=x_{1}$

$w\left(e_{i}^{\prime \prime}, t_{m}\right)=t_{m}+\delta_{m}$.

$G\left(e_{k}^{\prime \prime}\right)$ :

$Y=\left\{y_{1}\right\}, y_{1}=O_{k}\left(t_{m}\right)$.

Aggregate Embankments

1. Set of input signal. $X=\left\{x_{1}, x_{2}, x_{3}, x_{4}\right\}$, where $x_{i}=\left(O_{N}, O_{S}\right)$, where $x_{1}-$ the tanker has arrived for dark oil, $x_{2}$ - the tanker has arrived for light oil, $x_{3}$ - the dark oil, which will be taken out by arrived tanker, has been accumulated, $x_{4}$ - the light oil, which will be taken out by arrived tanker, has been accumulated.

2. Output signals. $Y=\left\{y_{1}, y_{2}\right\}$, where $y_{1}$-pouring of the dark oil to tanker has begun, $y_{2}$-pouring of the light oil to tanker has begun.

3. Set of external events. $E^{\prime}=\left\{e_{1}^{\prime}, e_{2}^{\prime}, e_{3}^{\prime}, e_{4}^{\prime}\right\}$.

4. Set of internal events. $E^{\prime \prime}=\left\{e_{1}^{\prime \prime}, e_{2}^{\prime \prime}\right\}$, where $e_{i}^{\prime \prime}-1$. the end of service of tanker in the $i$-th embankment.

5. Controlling sequences. Controlling sequences are not used.

6. Discrete component of state. $v(t)=\left(A_{D}(t), A_{L}(t)\right.$, $\left.S_{D}(t), S_{L}(t), Q_{D}(t), Q_{L}(t), \chi_{1}(t), \chi_{2}(t)\right)$, where indexes $D$ and $L$ are used for dark and light oil products correspondingly. $A_{D}(t), A_{L}(t)$ - the sets of tankers waiting for service, $S_{D}(t), S_{L}(t)$ - the sets of orders which can be served, $Q_{D}(t), Q_{L}(t)$ - the queues of tankers which can be served, $\chi_{1}(t)$ - the state of $i$-th embankment: 0 - embankment is idle, 1 - embankment is occupied by service of dark products; 2 embankment is occupied by service of light products.

7. Continuous part of state. $z_{v}(t)=\left(w\left(e_{1}^{n}, t\right), w\left(e_{2}^{n}, t\right)\right)$.

8. Initial state. $A_{D}\left(t_{0}\right)=A_{L}\left(t_{0}\right)=S_{D}\left(t_{0}\right)=S_{L}\left(t_{0}\right)=\varnothing$, $\# Q_{D}\left(t_{0}\right)=0, \# Q_{L}\left(t_{0}\right)=0, \chi_{1}\left(t_{0}\right)=0, \chi_{2}\left(t_{0}\right)=0$.

9. Transition and output operators. Operators for events $e_{1}^{\prime}, e_{3}^{\prime}$ and $e_{1}^{\prime \prime}$ are presented below. Operators for other events are similar and are not presented here.

$H\left(e_{1}^{\prime}\right)$ :

$S_{D}\left(t_{m}\right)=S_{D}\left(t_{m-1}\right) \backslash\left\{x_{1}\right\}$. if $x_{1} \in S_{D}\left(t_{m-1}\right)$ and $\chi_{1}\left(t_{m-1}\right) \chi_{2}\left(t_{m-1}\right) \neq 0$ then $Q_{D}\left(t_{m}\right)=\operatorname{enq}\left(Q_{D}\left(t_{m-1}\right), x_{1}\right)$, where enq - is operator of placing signal $x_{1}$ to queue if $x_{1} \in S_{D}\left(t_{m-1}\right)$ 


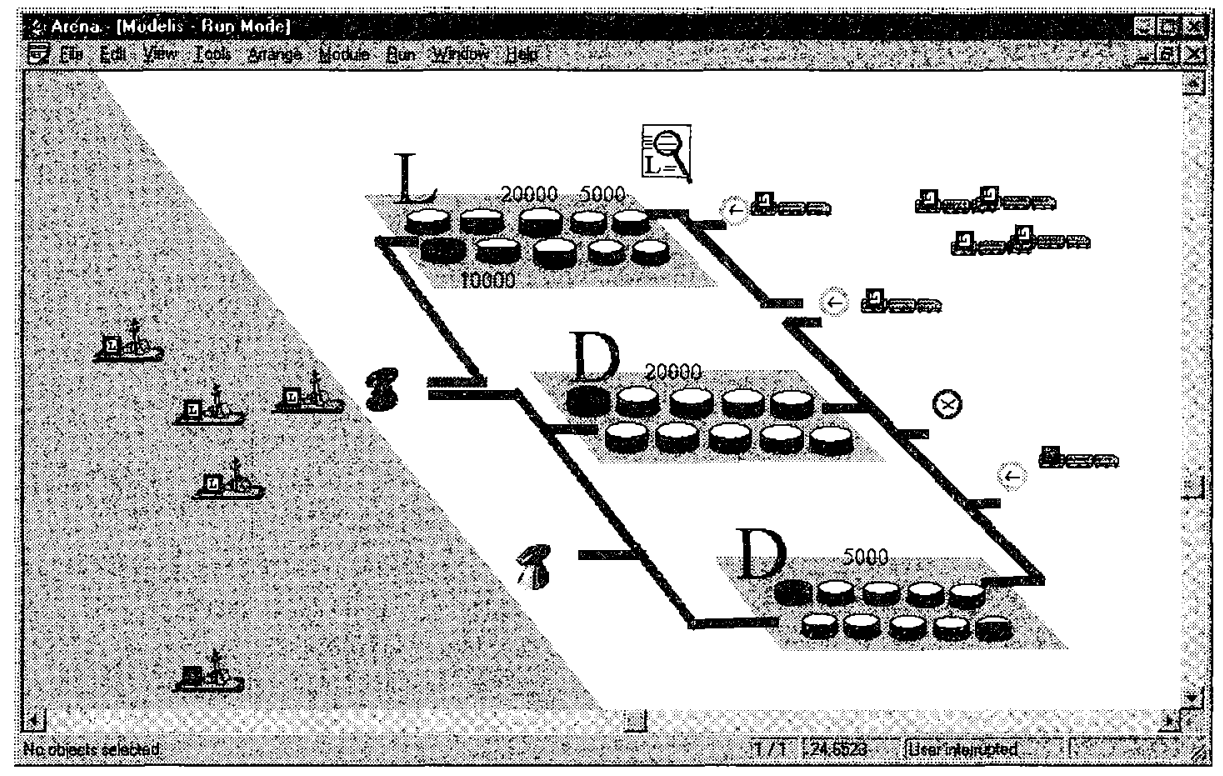

Fig 3. Graphical representation of the model

and $\chi_{1}\left(t_{m-1}\right)=0$ then $w\left(e_{1}^{\prime \prime}, t_{m}\right)=t_{m}+O_{s} / P_{E}$, where $P_{E}$ - pouring rate;

$$
\begin{aligned}
& \chi_{1}\left(t_{m}\right)=1 ; \\
& O_{1}\left(t_{m}\right)=x_{1} . \\
& \text { if } x_{1} \in S_{D}\left(t_{m-1}\right) \text { and } \chi_{1}\left(t_{m-1}\right) \neq 0 \text { and } \\
& \chi_{2}\left(t_{m-1}\right)=0 \text { then } \\
& w\left(e_{2}^{\prime \prime}, t_{m}\right)=t_{m}+O_{s} / P_{E} ; \\
& \chi_{2}\left(t_{m}\right)=1 ; \\
& O_{2}\left(t_{m}\right)=x_{1} .
\end{aligned}
$$$$
\text { if } x_{1} \notin S_{D}\left(t_{m-1}\right) \text { then }
$$$$
A_{D}\left(t_{m}\right)=A_{D}\left(t_{m}\right) \cup\left\{x_{1}\right\} \text {. }
$$$$
G\left(e_{1}^{\prime}\right) \text { : }
$$$$
\text { if } \chi_{1}\left(t_{m}\right) \neq \chi_{1}\left(t_{m-1}\right) \text { or } \chi_{2}\left(t_{m}\right) \neq \chi_{2}\left(t_{m-1}\right) \text { then }
$$$$
Y=\left\{y_{1}\right\}, y_{1}=x_{1} \text {. }
$$$$
H\left(e_{3}^{\prime}\right) \text { : }
$$

$$
A_{D}\left(t_{m}\right)=A_{D}\left(t_{m-1}\right) \backslash\left\{x_{3}\right\} .
$$

if $x_{3} \in A_{D}\left(t_{m-1}\right)$ and $\chi_{1}\left(t_{m-1}\right) \chi_{2}\left(t_{m-1}\right) \neq 0$ then

$$
Q_{D}\left(t_{m}\right)=\operatorname{enq}\left(Q_{D}\left(t_{m-1}\right), x_{3}\right) \text {. }
$$

if $x_{3} \in A_{D}\left(t_{m-1}\right)$ and $\chi_{1}\left(t_{m-1}\right)=0$ then

$$
\begin{aligned}
& w\left(e_{1}^{\prime \prime}, t_{m}\right)=t_{m}+O_{s} / P_{E} ; \\
& \chi_{1}\left(t_{m}\right)=1 ; \\
& O_{1}\left(t_{m}\right)=x_{3} .
\end{aligned}
$$

if $x_{3} \in A_{D}\left(t_{m-1}\right)$ and $\chi_{1}\left(t_{m-1}\right) \neq 0$ and

$\chi_{2}\left(t_{m-1}\right)=0$ then

$w\left(e_{2}^{\prime \prime}, t_{m}\right)=t_{m}+O_{s} P_{E}$

$\chi_{2}\left(t_{m}\right)=1$;

$O_{2}\left(t_{m}\right)=x_{3}$. if $x_{1} \notin A_{D}\left(t_{m-1}\right)$ then

$$
\begin{aligned}
& S_{D}\left(t_{m}\right)=S_{D}\left(t_{m}\right) \cup\left\{x_{3}\right\} . \\
& G\left(e_{3}^{\prime}\right):
\end{aligned}
$$

if $\chi_{1}\left(t_{m}\right) \neq \chi_{1}\left(t_{m-1}\right)$ or $\chi_{2}\left(t_{m}\right) \neq \chi_{2}\left(t_{m-1}\right)$ then $Y=\left\{y_{1}\right\} ; y_{1}=x_{3}$.

$$
H\left(e_{1}^{\prime \prime}\right) \text { : }
$$

if $\# Q_{D}\left(t_{m-1}\right)=0$ then

$$
\chi_{1}\left(t_{m}\right)=0 \text {. }
$$

if $\# Q_{D}\left(t_{m-1}\right)>0$ then

$$
Q_{D}\left(t_{m}\right)=\operatorname{deq}\left(Q_{D}\left(t_{m-1}\right)\right) ;
$$

where $d e q$ - is operator who removes the first element from the queue;

$$
O_{1}\left(t_{m}\right)=\left(O_{1}^{N}, O_{1}^{S}\right)=\operatorname{First}\left(Q_{D}\left(t_{m-1}\right)\right) ;
$$

where First - is the operator who returns the value of the first element of the queue;

$$
w\left(e_{1}^{\prime \prime}, t_{m}\right)=t_{m}+O_{1}^{S} / P_{E} .
$$

$G\left(e_{1}^{\prime \prime}\right)$ :

if $\# Q_{D}\left(t_{m-1}\right)>0$ then $Y=\left\{y_{1}\right\}, y_{1}=O_{1}\left(t_{m}\right)$.

\section{Simulation Results}

Formal specification of terminal was used developing a model with ARENA. New ARENA elements were created for each aggregate of specification. Template of new elements has been created using ARENA. Each element of the template represents aggregate from aggregate specification. The graphical representation of the model is presented in Fig 3.

Simulation results are got using the following parameters of the model:

1. Parameters of terminal input streams: 
a) Annual amount of transported oil.

\begin{tabular}{|l|c|c|c|c|c|c|}
\cline { 2 - 7 } \multicolumn{1}{c|}{} & \multicolumn{6}{c|}{ Experiment number } \\
\hline \multicolumn{1}{c|}{ Parameter } & 1 & 2 & 3 & 4 & 5 & 6 \\
\hline 1.a (kilotons) & 3500 & 4000 & 5000 & 6000 & 7000 & 8000 \\
\hline $\begin{array}{l}\text { Simulation } \\
\text { time (days) }\end{array}$ & 3650 & 3650 & 3650 & 3650 & 3650 & 3650 \\
\hline
\end{tabular}

b) Part of total amount of transported oil for each kind of oil.

c) Size of ordered oil.

d) Time interval during which oil products have to be delivered by trains.

e) Time interval after the start of service after which the tanker havs to arrive.

f) Number of wagons in a train.

g) Capacity of a wagon.

\begin{tabular}{|l|c|c|}
\cline { 2 - 3 } \multicolumn{1}{c|}{} & \multicolumn{2}{c|}{ Kind of oil product } \\
\hline Parameter & Light & Dark \\
\hline $1 . \mathrm{b}$ & $40 \%$ & $60 \%$ \\
\hline $1 . \mathrm{c}$ (kilotons) & {$[10,12]$} & {$[25,30]$} \\
\hline $1 . \mathrm{d}$ (days) & {$[1,3]$} & {$[1,3]$} \\
\hline $1 . \mathrm{e}$ (days) & 5 & 5 \\
\hline $1 . \mathrm{f}$ (tonne) & 50 & 50 \\
\hline $1 . \mathrm{g}$ (tonne) & 50 & 50 \\
\hline
\end{tabular}

2. Parameters characterizing the structure of terminal:

a) Number of reservoirs and their capacities which are used for each kind of oil.

b) Number of platforms.

c) Subsets of platforms used to serve different kinds of oil.

d) Number of wagons in each platform which can be served at the same time.

\begin{tabular}{|l|c|c|}
\cline { 2 - 3 } \multicolumn{1}{c|}{} & \multicolumn{2}{c|}{ Kind of oil product } \\
\hline 2.a (tonne) & Light & Dark \\
\hline Tanks capacities: & 20 & 10 \\
Tank_1-2 & 20000 & 20000 \\
Tank_3-6 & 20000 & 10000 \\
Tank_7-10 & 20000 & 5000 \\
Tank_11-20 & 5000 & \\
\hline 2.b,2c & \multicolumn{2}{|c|}{4} \\
\hline Platforms system: & - & Yes \\
Platform_1-2 & Yes & Yes \\
Platform_3 & Yes & - \\
Platform_4 & \multicolumn{2}{|c|}{} \\
\hline 2.e & - & Yes \\
\hline Embankment system: & Yes & Yes \\
\hline Embankment_1 &
\end{tabular}

e) Subsets of embankments used to serve different kinds of oil.

3. Technological parameters of the terminal:

a) Time during which oil products are poured from wagons to reservoirs for each kind of oil

b) Rate of pouring oil from reservoirs to a tanker

4. Parameters characterizing the control of terminal:

a) Order of performance decision-making algorithm, which evaluates the number of wagons, which are in railway station.

b) Order of performance decision-making algorithm, which does not evaluate the number of wagons, which are at railway station.

c) Algorithm carrying orders of tankers and evaluating only needed amount of empty reservoir for the realization of order.

d) Algorithm carrying orders of tankers and evaluating needed amount of empty reservoir for the realization of order and number of wagons at the railway station.

\begin{tabular}{|l|c|c|}
\cline { 2 - 3 } \multicolumn{1}{c|}{} & \multicolumn{2}{c|}{ Kind of oil product } \\
\hline Parameter & Light & Dark \\
\hline 3.b (kilotons/day) & 4 & 8 \\
\hline 4.a & 25 & 25 \\
\hline 4.b & - & - \\
\hline 4.c & - & - \\
\hline 4.d & - & - \\
\hline
\end{tabular}

Fig 4 depicts dependencies of platforms occupation with respect to the transported amount of oil. Fig 5 depicts similar dependencies of embankments.

Simulation results show that up to 8 megatons per year of oil products can be transported through the Klaipeda oil terminal.

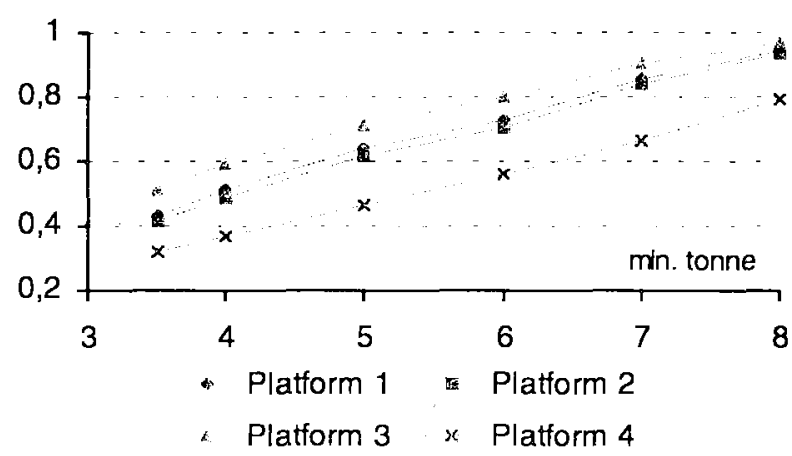

Fig 4. Dependencies of platform occupation with respect to the transported amount of oil 


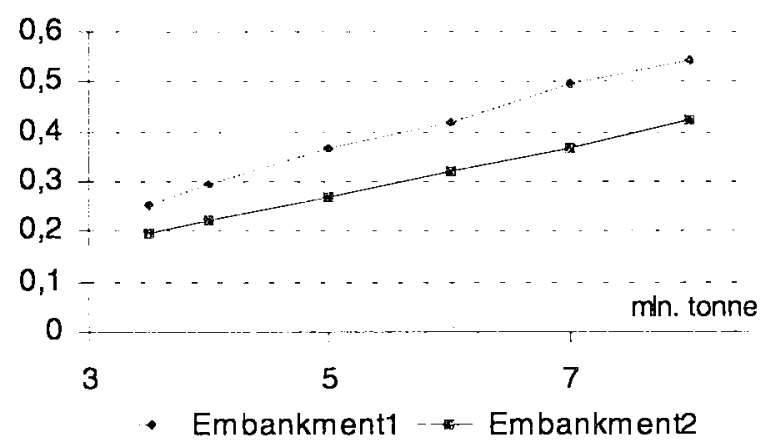

Fig 5. Dependencies of embankments occupation with respect to the transported amount of oil

Figs 6-8 depict distribution functions service time for order $\left(t_{\mathrm{O}}\right)$, tank-wagon $\left(t_{\mathrm{W}}\right)$ and tanker $\left(t_{\mathrm{T}}\right)$. Each dependency has been evaluated at the different amounts of oil transported through terminal per year.

Fig 9 depicts dependences of mean volume in reservoirs for dark and light oil with respect to transportation amount of oil.

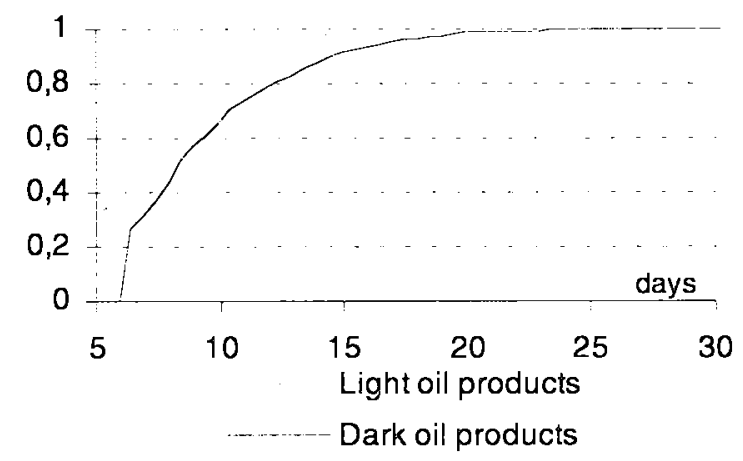

Fig 6. Distribution function service time for order for different kinds of oil product. (transportation amount is 6 megatons)

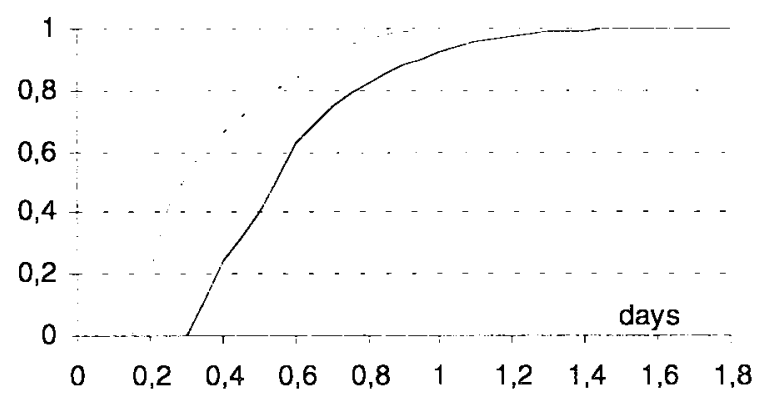

Light oil products --_ Dark oil products

Fig 7. Distribution function service time for tank-wagon for different kinds of oil products (transportation amount is 6 megatons)
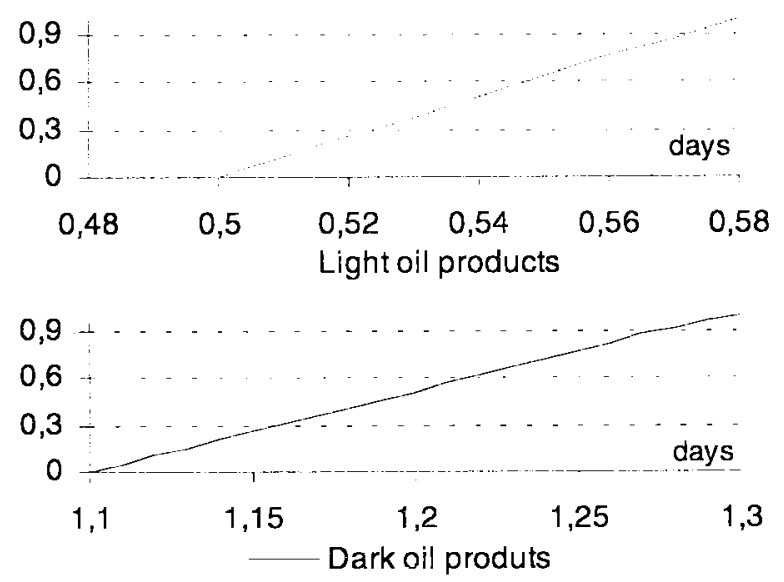

Fig 8. Distribution function service time for tanker for different kinds of oil products. (transportation amount is 6 megatons)

\section{Conclusion}

The presented simulation approach permits to combine advantages of formal methods and simulation system ARENA developing simulation models for the analysis of stevedoring work in oil terminal. Formal specification permits to describe the simulated system mathematically strictly. ARENA system permits to realize software implementation and animation of the developed model.

\section{References}

1. Giribone, P., Bruzzone, G. A., Corbone, A. Harbour services and lay-out re-engineering by using simulation. In: International Workshop "Modelling and Simulation Within a Maritime Environment", Riga, September 6-8, 1998, p 3-7.

2. Giribone, P., Bruzzone, A.G. and Caddeo, S. Oil spill and AI: how to manage the resources by using simulation. In: Proceedings of TIEMEC'95 (Nice, May 9-12), 1995.

3. Tolujev, J., Lopatenok, T., Lopatenok, V. Oil terminal simulation for demonstration and training. In: International Workshop "Modelling and Simulation Within a Maritime Environment", Riga, September 6-8, 1998, p 86-90.

4. Pranevičius, H., Pilkauskas, V., Makackas, D. Interaction of various kinds of transportation at Klaipeda Harbour. In: Proceedings: The International Workshop "Harbour, Maritime \& Industrial Logistics Modelling and Simulation", Genoa, September 16-18, 1999, p 124-129.

5. Pranevičius, H., Makackas, D. 2000. The Use of Aggregate Approach for Formal Specification and Simulation of RealTime System. In: Database and Information Systems, Kluwer Academic Publishers, 2001, p 189-198.

6. Pranevičius, $H$. Aggregate approach for specification, validation, simulation and implementation of computer network protocols. In: Lecture Notes in Computer Science, No 502, Springer-Verlag, 1992, p 433-477.

7. Pranevicius H. Formal specification and analysis of distributed systems. Journal of Intiligent Manufacturing, N 9, 1998. 